\title{
CONTRIBUTION TO THE STUDY OF FLUID FLOW IN A STIRRED
}

\section{TANK BY INTRODUCING MICROPARTICLES}

\section{N. SEGHOUANI ${ }^{1}$, L. RAHMANI ${ }^{1}$, A. BENMOUSSA ${ }^{1}$, O. SEGHIER $^{1}$,}

\section{A. TAFRAOUI ${ }^{2} \&$ B. DRAOUI ${ }^{1}$}

${ }^{I}$ Department of Mechanical Engineering, University TAHRI Mohamed BECHAR, Arids Zones Energetic Laboratory (ENERGARID), Algeria

${ }^{2}$ Department of Mechanical Engineering, University TAHRI Mohamed BECHAR, Mechanical Engineering Reliability Laboratory (LFGM), Algeria

Micro particles are today a major technological and economic issue. They enable very promising innovations in many fundamental areas such as: health, energy or industry. Despite the numerous studies devoted to hydrodynamics in agitated tanks, there is still a glaring lack of information on the temporal evolution of fluid flow properties. The knowledge of this dependence has been often crucial, for example, in the food, chemical, biochemical or petrochemical industry is carried out in tanks or in mechanically agitated reactors. The micro particles are colloidal solutions composed of particles of micrometric size suspended in a liquid. Their astonishing thermal properties have been the subject of intense investigation during the last decade. It is proposed in this work to study the influence of the concentration of micro particles (al2o3, cuo, etc.) Dispersed in a base fluid on the hydrodynamic fields of fluid in flat-bottomed cylindrical and non-quenched fluid provided with a stirrer. Anchor type was undertaken by numerical simulation using the fluent cfd 6.2.13 based on the finite volume discretization method of the navier stokes equations (uvp) equations and the energy equation. We aim at a synthesis of the simulated system by comparing the power consumed by the micro particle technique.
\end{abstract}

KEYWORDS: Mechanical Agitation, Finite Volume Method, Paddle Stirrers, Anchor, Laminar Flow, Micro Particle \& Cfd Modeling

Received: Jun 13, 2018; Accepted: Jul 04, 2018; Published: Aug 01, 2018; Paper Id.: IJMPERDOCT201824

\section{INTRODUCTION}

In recent years a new type of fluid is emerging: the nanofluid. The nanofluid is a coolant such as water, the oil to which is added nanoparticles of metal $\left(\mathrm{Al}, \mathrm{Cu}, \mathrm{Ag}\right.$, $\mathrm{Au}$, etc.) or metal or non-metallic oxide $\left(\mathrm{SiO}_{2}, \mathrm{Al}_{2} \mathrm{O}_{3}\right.$, $\mathrm{TiO}_{2}$ ), and other (allotropic forms of carbon) in relatively small amounts $(0.1$ to $6 \%$ of the total volume) [1].

Nanofluids are a new fluid category that was introduced for the first time by Choi [2, 3]. Indeed, it involves dispersing nanoscale particles in conventional fluids commonly used, in order to improve the properties of the latter. Nanofluids are generally classified according to the nature of the nanoparticles that compose them in three categories, namely, metal, metallic and non-metallic oxide $[4,5]$. Nanofluids find their applications in several sectors, including domestic, engineering and biomedicine.

The development of nanotechnologies is a challenge for the years to come [6]. Nanoscience studies the structure of matter at the molecular level, therefore at the nanoscale, with the aim of innovating in many fields such 
as: the environment, the production and storage of energy, the cooling of electronic components, biology, medical diagnosis, water treatment, etc [7, 8, and 9].

Microparticles will be today a major technological and economic issue. They enable very promising innovations in many fundamental areas such as: health, energy or industry [10, 11, and 12]. Despite the many studies devoted to hydrodynamics in agitated reservoirs, there is still a glaring lack of information on the temporal evolution of the flow properties of fluids [13,14, and 15]. The knowledge of this dependence is often crucial for example in the food, chemical, biochemical or petrochemical industry is carried out in tanks or in mechanically agitated reactors [16, 17, 18, and 19]. The micro particles are colloidal solutions composed of particles of micrometric size suspended in a liquid. Their amazing thermal properties have been the subject of intense research over the last decade [20, 21, 22, and 23].

The main objective of the present work is to study the influence of the concentration of micro particles $\left(\mathrm{Al}_{2} \mathrm{O}_{3}\right.$, $\mathrm{CuO}$, etc.) dispersed in a base fluid on the hydrodynamic fields of the fluid in a cylindrical and non-hardened flat-bottom fluid provided by an agitator. The type of anchoring was done by numerical simulation using the CFD 6.2.13 method based on the finite volume discretization method of the Navier Stokes equations (UVP) and the energy equation. We aim at a synthesis of the simulated system by comparing the power consumed by the microparticle technique.

Many industries (chemical, pharmaceutical and food) use, produce or transform complex fluids. These are high viscosity fluids, often with non-Newtonian behaviour. Their preparation generally requires a heating step followed by a cooling step. Heating is essential to facilitate manufacture (chemical reaction and / or physical-chemical transformation) $[24,25$, and 26].

The cooling or the finishing step consists in bringing the fluids to a temperature close to ambient temperature in order to approach the conditioning step. The cooling is most often carried out in the same stirred tank [27].

There are two strong demands in the industry: firstly, ensure the quality of finished products. Secondly, work in a more and more concentrated environment for pollution and cost problems, in order to know and check all the involved aspects in the process, in particular hydrodynamics and heat transfer [28, 29].

\section{NUMERICAL MODELS}
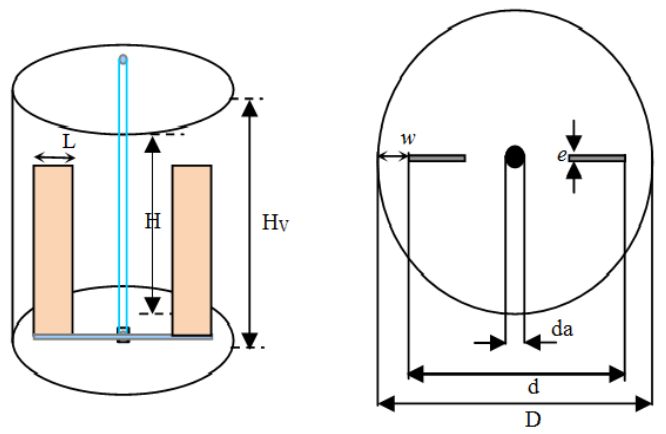

Figure 1: The Geometry of Mixing System

The mixing systems are presented in figure1. The tank is a flat-bottomed vessel (inside diameter: D) equipped with an anchor agitator (diameter d). $\mathrm{H}$ is the fluid height. Values for the agitator width 'L', agitator-to-wall clearance ' $w$ ', impairs thickness 'e' and geometrical characteristics are reported in Table1. 
Table1: Geometrical Characteristics of the Agitator

\begin{tabular}{|c|c|c|c|c|c|}
\hline D & d & da & e & L & w \\
\hline 1 & 0.96 & 0.023 & 0.027 & 0.067 & 0.04 \\
\hline
\end{tabular}

\section{MODEL EQUATIONS AND COMPUTATIONAL PROCEDURE}

The equations describing fluid flow are derived from the conservation of mass and momentum which are also known as Navier-Stokes equations for fluids of constant physical properties [1, 30]:

Continuity:

$\operatorname{div} \vec{V}=0$

$\frac{\partial U}{\partial x}+\frac{\partial V}{\partial y}=0$

Momentum:

$\left.\rho_{n f}\left[\frac{\partial \vec{V}}{\partial t}+\vec{V} \cdot \nabla \vec{V}\right]=-\nabla \vec{P}+\mu_{n f} \Delta \vec{V}\right]$

On the $\mathrm{X}$ axis:

$\rho_{n f}\left[\frac{\partial U}{\partial t}+U \frac{\partial U}{\partial x}+V \frac{\partial U}{\partial y}\right]=-\frac{\partial P}{\partial x}+\mu_{n f}\left[\frac{\partial^{2} U}{\partial^{2} x}+\frac{\partial^{2} U}{\partial^{2} y}\right]$

On the $\mathrm{Y}$ axis:

$\rho_{n f}\left[\frac{\partial V}{\partial t}+U \frac{\partial V}{\partial x}+V \frac{\partial V}{\partial y}\right]=-\frac{\partial P}{\partial x}+\mu_{n f}\left[\frac{\partial^{2} V}{\partial^{2} x}+\frac{\partial^{2} V}{\partial^{2} y}\right]$

Density:

$\rho_{n f}=\phi \rho_{S}+(1-\phi) \rho_{f}$

And

The viscosity of the nanofluid is given by Brinkman [1]:

$\mu_{n f}=\frac{\mu_{f}}{(1-\phi)^{2.5}}$

The variables of the previous equations are dimensional as follows:

$$
\begin{aligned}
& \left(x^{*}, y^{*}\right)=\frac{(x, y)}{R},\left(U^{*}, V^{*}\right)=\frac{(U, V)}{2 \pi N R V_{0}} \\
& P^{*}=\frac{P}{4 \pi^{2} N^{2} R^{2} \rho_{f}}=\frac{P}{\rho_{n f} \cdot V_{0}^{2}}
\end{aligned}
$$

In dimensionless form: 
$\frac{\partial U^{*}}{\partial x^{*}}+\frac{\partial V^{*}}{\partial y^{*}}=0$

$\rho_{n f}\left[\frac{V_{0}^{2}}{R}+\left(U^{*} \cdot \frac{\partial U^{*}}{\partial x^{*}}+V^{*} \cdot \frac{\partial U^{*}}{\partial y^{*}}\right)\right]=-\frac{\rho_{f} V_{0}^{2}}{R} \cdot \frac{\partial P^{*}}{\partial x^{*}}+\mu_{n f} \cdot \frac{V_{0}}{R^{2}}\left[\frac{\partial^{2} U^{*}}{\partial^{2} x^{*}}+\frac{\partial^{2} U^{*}}{\partial^{2} y^{*}}\right]$

(10)

$$
\begin{aligned}
& \rho_{n f}\left[\frac{V_{0}^{2}}{R}+\left(U^{*} \cdot \frac{\partial V^{*}}{\partial x^{*}}+V^{*} \cdot \frac{\partial V^{*}}{\partial y^{*}}\right)\right]=-\frac{\rho_{f} V_{0}^{2}}{R} \cdot \frac{\partial P^{*}}{\partial x^{*}}+\mu_{n f} \cdot \frac{V_{0}}{R^{2}}\left[\frac{\partial^{2} V^{*}}{\partial^{2} x^{*}}+\frac{\partial^{2} V^{*}}{\partial^{2} y^{*}}\right] \\
& U^{*} \cdot \frac{\partial U^{*}}{\partial x^{*}}+V^{*} \cdot \frac{\partial U^{*}}{\partial y^{*}}=-\frac{\rho_{f}}{\rho_{n f}} \cdot \frac{\partial P^{*}}{\partial x^{*}}+\frac{\mu_{n f}}{\rho_{n f} \cdot V_{0} \cdot R}+\left[\frac{\partial^{2} U^{*}}{\partial^{2} x^{*}}+\frac{\partial^{2} U^{*}}{\partial^{2} y^{*}}\right] \\
& U^{*} \cdot \frac{\partial V^{*}}{\partial x^{*}}+V^{*} \cdot \frac{\partial V^{*}}{\partial y^{*}}=-\frac{\rho_{f}}{\rho_{n f}} \cdot \frac{\partial P^{*}}{\partial y^{*}}+\frac{\mu_{n f}}{\rho_{n f} \cdot V_{0} \cdot R}\left[\frac{\partial^{2} V^{*}}{\partial^{2} x^{*}}+\frac{\partial^{2} V^{*}}{\partial^{2} y^{*}}\right] \\
& \frac{\rho_{n f}}{\rho_{f}}\left(U^{*} \cdot \frac{\partial U^{*}}{\partial x^{*}}+V^{*} \cdot \frac{\partial U^{*}}{\partial y^{*}}\right)=-\frac{\partial P^{*}}{\partial x^{*}}+\frac{\mu_{n f}}{\rho_{f} \cdot V_{0} \cdot R}\left[\frac{\partial^{2} U^{*}}{\partial^{2} x^{*}}+\frac{\partial^{2} U^{*}}{\partial^{2} y^{*}}\right] \\
& \frac{\rho_{n f}}{\rho_{f}}\left(U^{*} \cdot \frac{\partial V^{*}}{\partial x^{*}}+V^{*} \cdot \frac{\partial V^{*}}{\partial y^{*}}\right)=-\frac{\partial P^{*}}{\partial y^{*}}+\frac{\mu_{n f}}{\rho_{f} \cdot V_{0} \cdot R}\left[\frac{\partial^{2} V^{*}}{\partial^{2} x^{*}}+\frac{\partial^{2} V^{*}}{\partial^{2} y^{*}}\right] \\
& U^{*} \cdot \frac{\partial V^{*}}{\partial x^{*}}+V^{*} \cdot \frac{\partial V^{*}}{\partial y^{*}}=-\frac{\partial P^{*}}{\partial y^{*}}+\frac{\mu_{n f}}{\rho_{f} \cdot V_{0} \cdot R}\left[\frac{\partial^{2} V^{*}}{\partial^{2} x^{*}}+\frac{\partial^{2} V^{*}}{\partial^{2} y^{*}}\right] \\
& U_{n}^{*} \cdot \frac{\partial U^{*}}{\partial y^{*}}=-\frac{\partial P^{*}}{\partial x^{*}}+\frac{\mu_{n f}}{\rho_{f} \cdot V_{0} \cdot R}\left[\frac{\partial^{2} U^{*} x^{*}}{\partial^{2} y^{*}}\right]
\end{aligned}
$$

The Reynolds number is defined by

$$
\operatorname{Re}=\frac{\rho_{f} \cdot V_{0} \cdot R}{\mu_{f}}
$$

Finally the equation of the amount of movement along the $\mathrm{X}$ and $\mathrm{Y}$ axis is:

$$
\begin{aligned}
& U^{*} \cdot \frac{\partial U^{*}}{\partial x^{*}}+V^{*} \cdot \frac{\partial U^{*}}{\partial y^{*}}=-\frac{\partial P^{*}}{\partial x^{*}}+\frac{\mu_{n f}}{\mu_{f}} \cdot \frac{\rho_{f}}{\rho_{n f}} \cdot \frac{\mu_{f}}{\rho_{f} \cdot V_{0} \cdot R}\left[\frac{\partial^{2} U^{*}}{\partial^{2} x^{*}}+\frac{\partial^{2} U^{*}}{\partial^{2} y^{*}}\right] \\
& U^{*} \cdot \frac{\partial V^{*}}{\partial x^{*}}+V^{*} \cdot \frac{\partial V^{*}}{\partial y^{*}}=-\frac{\partial P^{*}}{\partial y^{*}}+\frac{\mu_{n f}}{\mu_{f}} \cdot \frac{\rho_{f}}{\rho_{n f}} \cdot \frac{\mu_{f}}{\rho_{f} \cdot V_{0} \cdot R}\left[\frac{\partial^{2} V^{*}}{\partial^{2} x^{*}}+\frac{\partial^{2} V^{*}}{\partial^{2} y^{*}}\right] \\
& U^{*} \cdot \frac{\partial U^{*}}{\partial x^{*}}+V^{*} \cdot \frac{\partial U^{*}}{\partial y^{*}}=-\frac{\partial P^{*}}{\partial x^{*}}+\frac{B}{A} \cdot \frac{1}{\operatorname{Re}}\left[\frac{\partial^{2} U^{*}}{\partial^{2} x^{*}}+\frac{\partial^{2} U^{*}}{\partial^{2} y^{*}}\right]
\end{aligned}
$$




$$
\begin{aligned}
& U^{*} \cdot \frac{\partial V^{*}}{\partial x^{*}}+V^{*} \cdot \frac{\partial V^{*}}{\partial y^{*}}=-\frac{\partial P^{*}}{\partial y^{*}}+\frac{B}{A} \cdot \frac{1}{\operatorname{Re}}\left[\frac{\partial^{2} V^{*}}{\partial^{2} x^{*}}+\frac{\partial^{2} V^{*}}{\partial^{2} y^{*}}\right] \\
& \frac{\rho_{n f}}{\rho_{f}}=\phi \cdot \frac{\rho_{S}}{\rho_{f}}+(1-\phi)=A \\
& \frac{\mu_{n f}}{\mu_{f}}=\frac{1}{(1-\phi)^{2.5}}=B
\end{aligned}
$$

\subsection{Boundary Conditions}

In the CFD code used two reference frames can be treated. One is stationary, the impeller is in rotation and the tank is fixed. The other frame, which is rotating, the impeller is kept stationary while the outer wall of the vessel is given an angular velocity equal and opposite to the velocity of the rotating frame. Constant boundary conditions have been set respecting a fixed reference frame (RRF) approach. The boundary conditions for velocity are fixed on the gate impeller and the vessel. On the gate impeller: Moving reference frame implemented in the CFD code.

\subsection{Validation}

To verify the model of the fluid and to validate our results we compared our power number with previous works on an anchor agitator. Figure 2 gives an example of comparison between our results and a numerical work of Marouche [15]. The results show a satisfactory agreement.

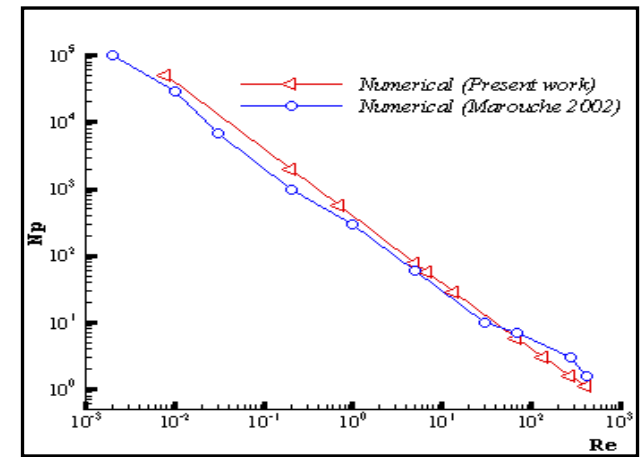

Figure 2: Variation of Power Number as Function of Reynolds Number

\section{RESULTS AND INTERPRETATIONS}

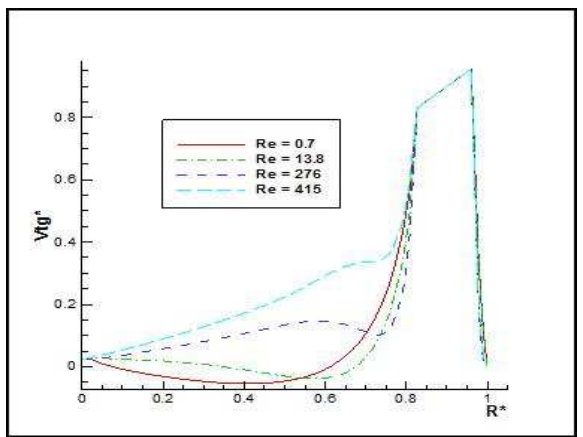

Figure 3: Tangential Velocity on the Blade and its Extension according to $\mathrm{Re}$ for $\mathrm{C}=\mathbf{2 0 \%}$

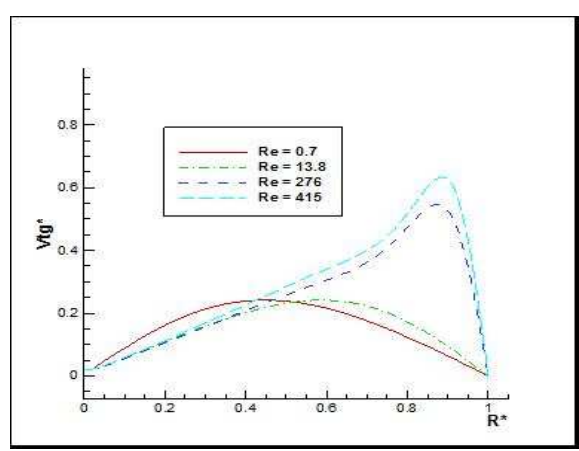

Figure 4: Tangential Velocity on the Mediator according to $\operatorname{Re}$ for $\mathrm{C}=\mathbf{2 0 \%}$. 


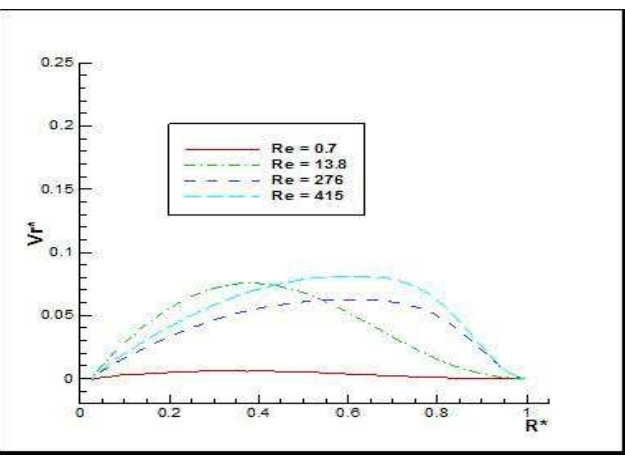

Figure 5: Radial Velocity on the Mediator According to $\operatorname{Re}$ for $\mathrm{c}=\mathbf{2 0 \%}$.

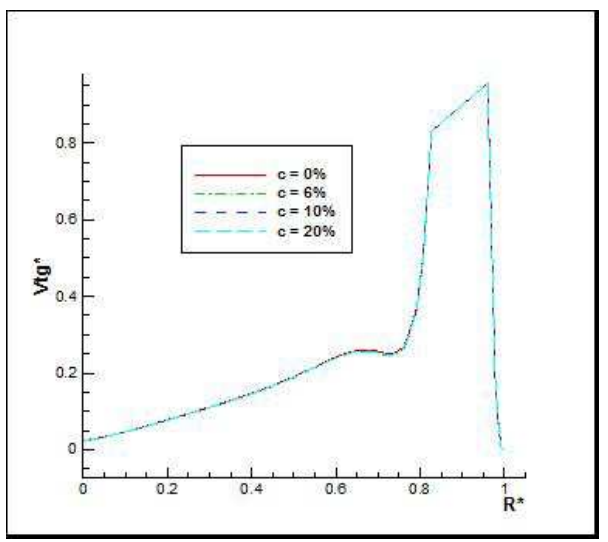

Figure 7: Tangential Velocity on the Blade and its Extension according to Concentration $\mathrm{C}$

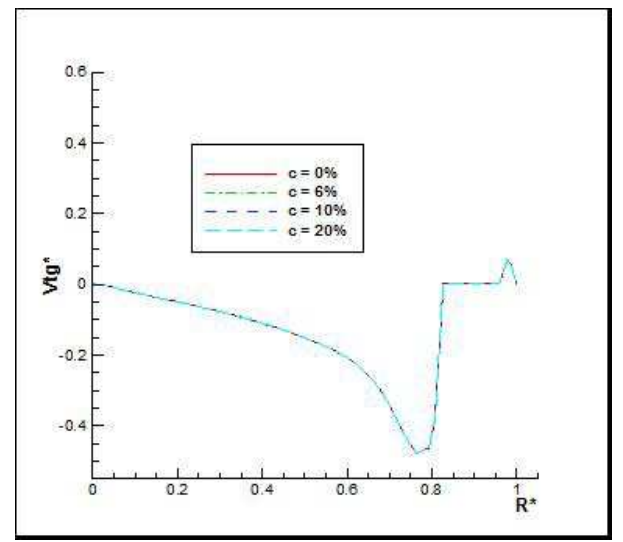

Figure 9: Radial Velocity on the Blade and its Extension as a Function of Concentration C

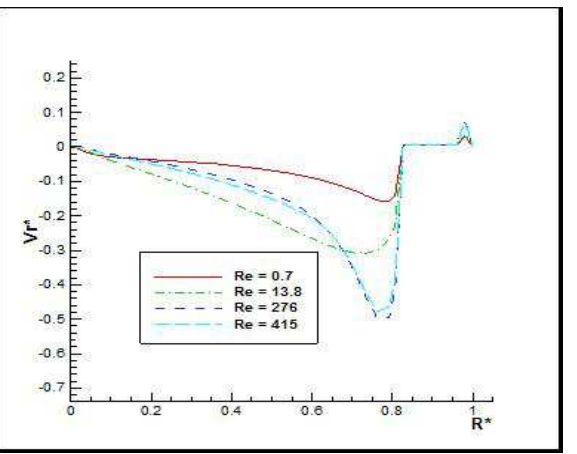

Figure 6: Radial Velocity on the Blade and its Extension According to $\mathrm{Re}$ for $\mathrm{C}=\mathbf{2 0 \%}$.

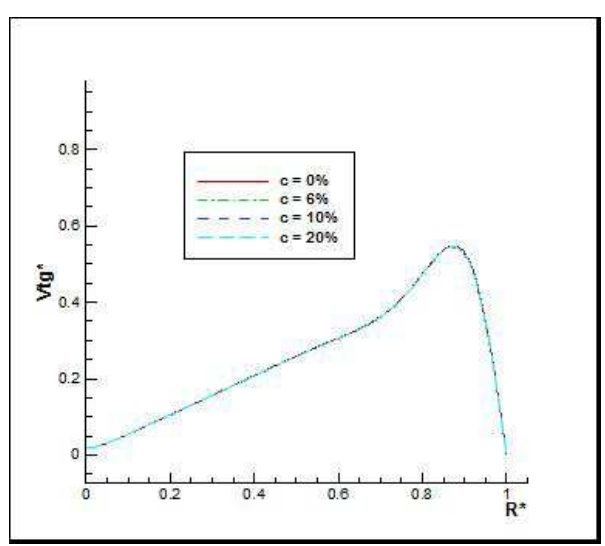

Figure 8: Tangential Velocity on the Mediator according to Concentration $\mathrm{C}$

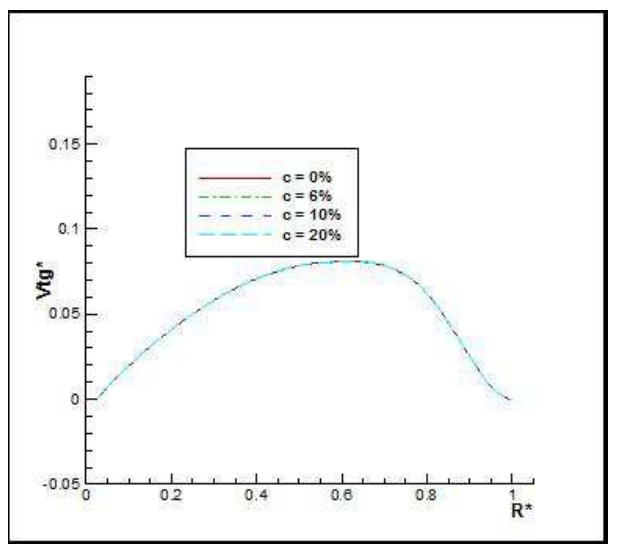

Figure 10: Radial Velocity on the Mediator as a Function of Concentration C (CUO) 


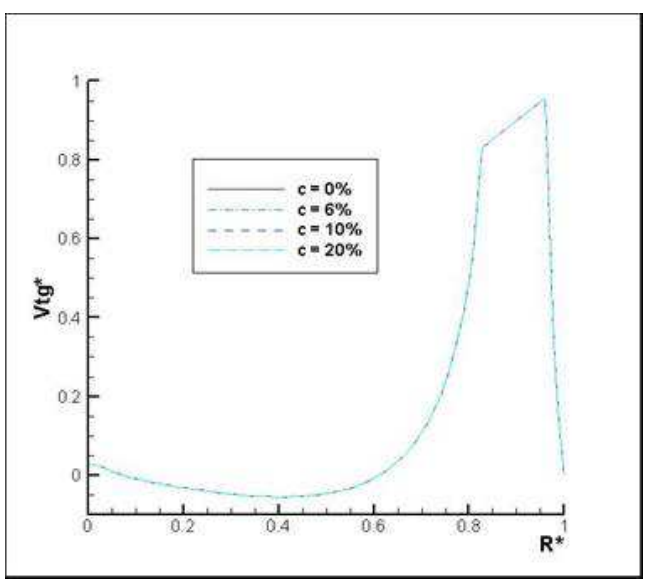

Figure 11: Tangential Velocity on the Blade and its Extension as a Function of Concentration for $\operatorname{Re}=415\left(\mathrm{Al}_{2} \mathrm{O}_{3}\right)$

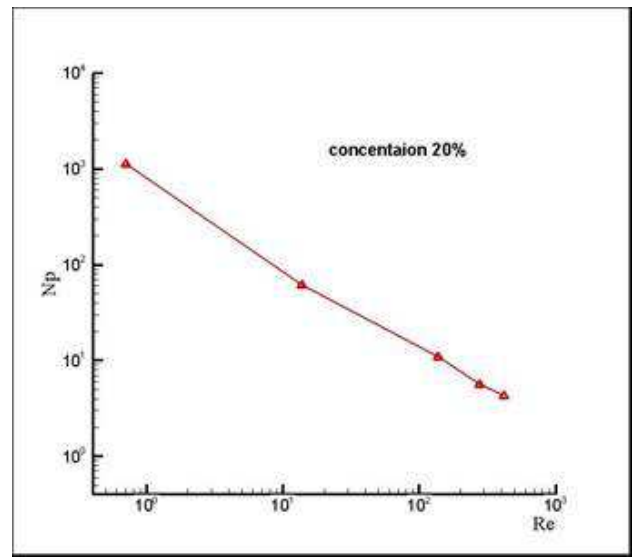

Figure 13: Variation of $\mathrm{Np}$ as a Function of Re with a Concentration of $20 \%$ for $\left(\mathrm{Al}_{2} \mathrm{O}_{3}\right)$

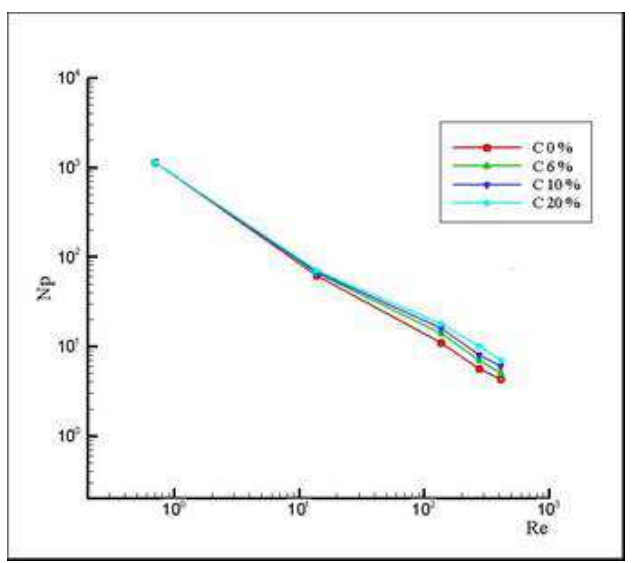

Figure 15: Variation of $\mathrm{Np}$ according to $\mathrm{Re}$ for different Concentration $\left(\mathrm{Al}_{2} \mathrm{O}_{3}\right)$

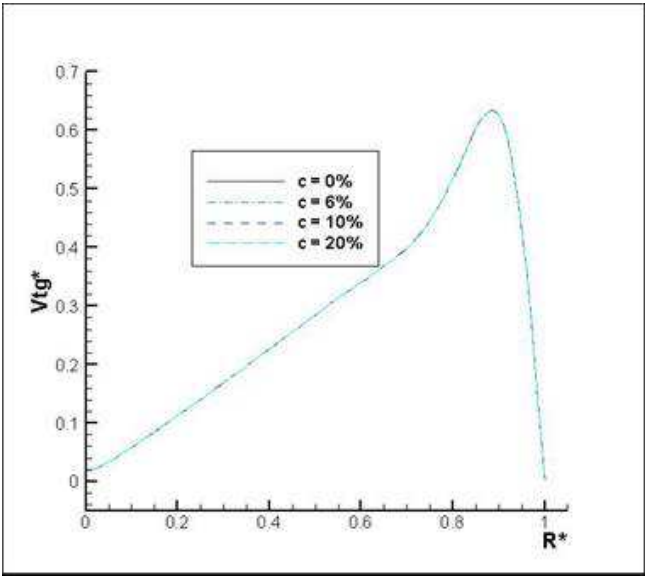

Figure 12: Tangential Velocity on the Pale Mediator and its Extension as a Function of Concentration for $\operatorname{Re}=\mathbf{4 1 5}$

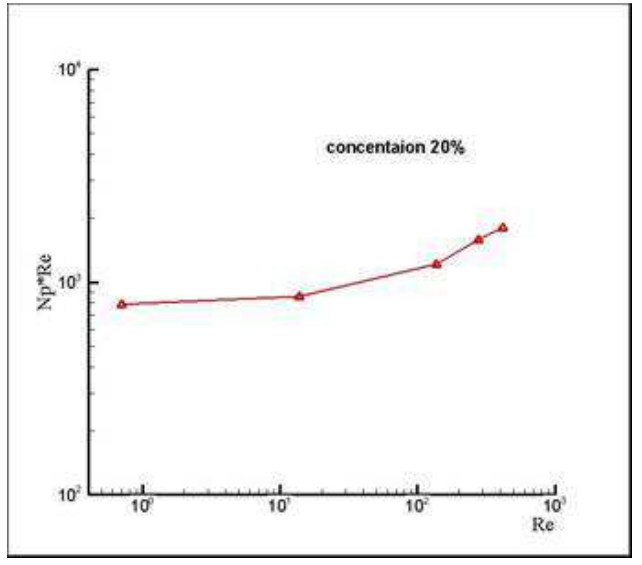

Figure 14: Variation of $\mathrm{Np} * \mathrm{Re}$ as a Function of $\mathrm{Re}$ with a Concentration of $20 \%$ for $\left(\mathrm{Al}_{2} \mathrm{O}_{3}\right)$

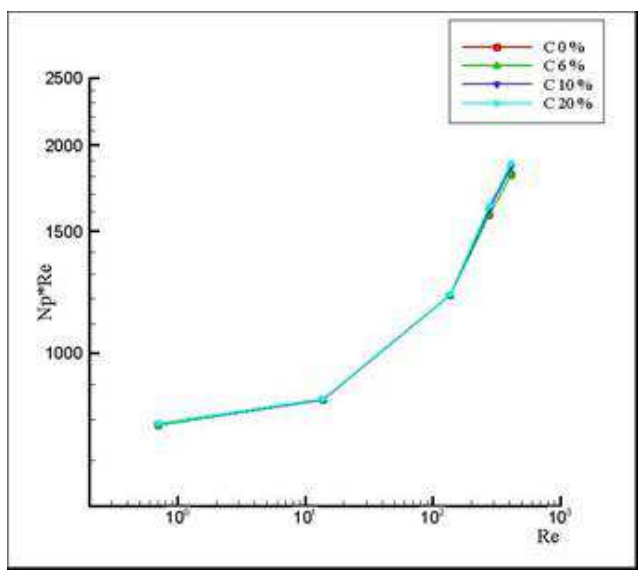

Figure 16: Variation of $\mathrm{Np} * \mathrm{Re}$ according to Re for different Concentration $\left(\mathrm{Al}_{2} \mathrm{O}_{3}\right)$ 


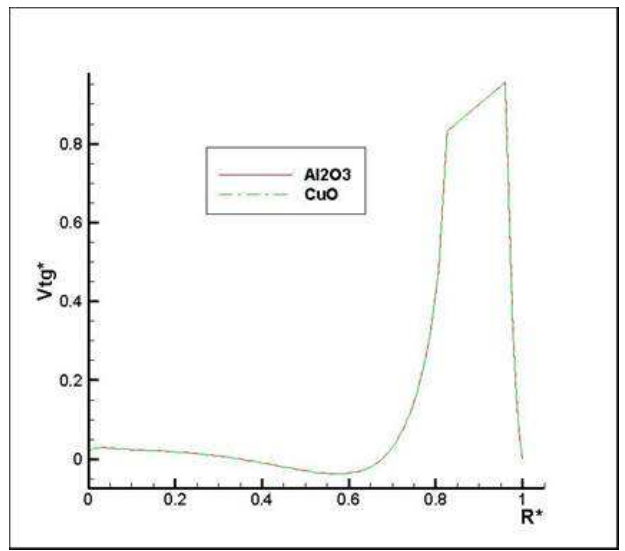

Figure 17: Variation of the Tangential Velocity on the blade and its extension for $\left(\mathrm{Al}_{2} \mathrm{O}_{3}\right)$ and $(\mathrm{CuO})$ for $\mathrm{Re}=415$

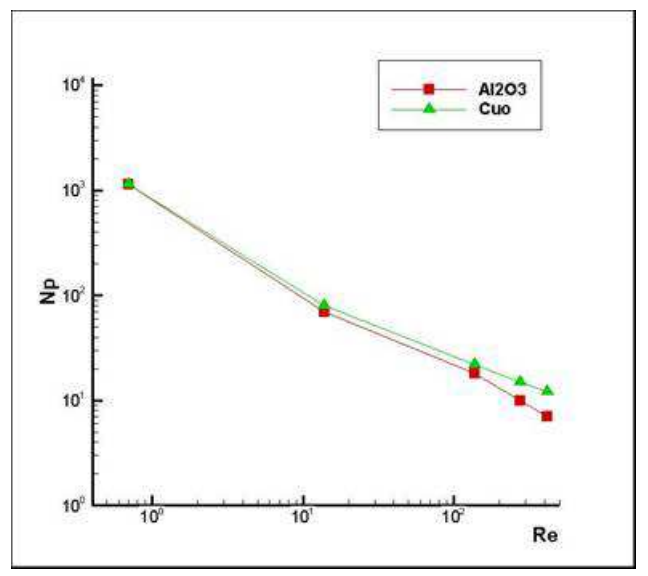

Figure 19: Variation of $\mathrm{Np}$ as a Function of Figure 20: Variation of $\mathrm{Np} * \mathrm{Re}$ as a Function $\operatorname{Re}$ for $\left(\mathrm{Al}_{2} \mathrm{O}_{3}\right)$ and $(\mathrm{CuO})$

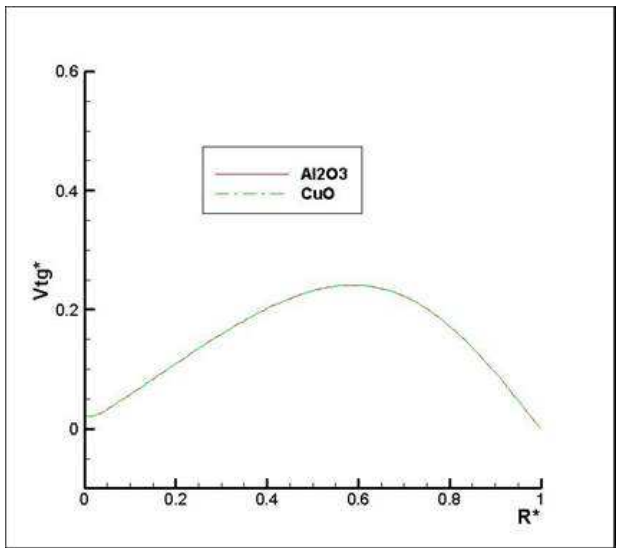

Figure 18: Radial Velocity Variation on the Blade and its extension for $\left(\mathrm{Al}_{2} \mathrm{O}_{3}\right)$ and $(\mathrm{CuO})$ for $\mathrm{Re}=415$

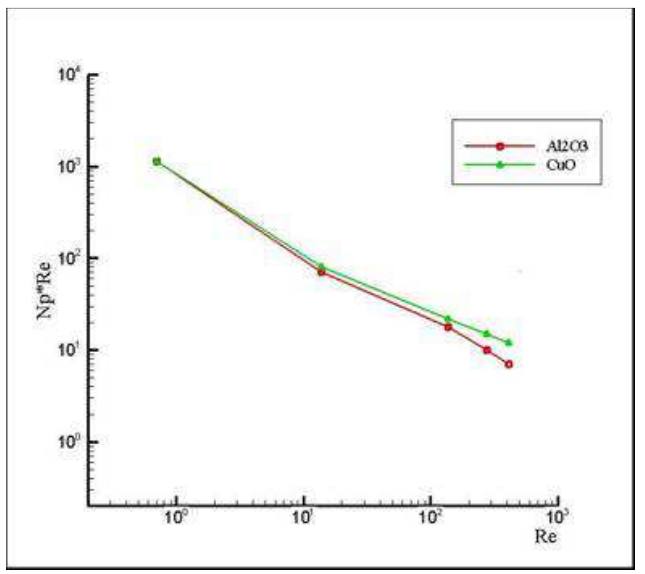
of $\operatorname{Re}$ for $\left(\mathrm{Al}_{2} \mathrm{O}_{3}\right)$ and $(\mathrm{CuO})$

Les Figures 3, 4, 5, 6 and 7 show the variation of the tangential and radial velocity of the agitator and its extension and on the mediator according to the radial position. We studied the influence of Reynolds number on the nature of the flow by varying this parameter from 0.7 to 415 for nanoparticle concentration $\mathrm{C}=20 \%$. The tangential component of the velocity varies in the following manner (Figure 3).

The tangential component of the velocity varies as follows: the growth of the tangential velocity of the shaft of the agitator at the end of the blade a linear increase between its two ends, once completed, a sudden decrease in the velocity of the wall of the tank which is null. It is noted again that the tangential velocity increases with the increase of the Reynolds number.

It is noted that upstream of the blade the tangential velocity $\mathrm{Vt}^{*}$ is negative for the low Reynolds numbers, when Re is large enough, the tangential velocity is always positive, against the radial velocity $\mathrm{Vr}^{*}$ : this means that the end of the blade sucks the fluid from the center of the wall of the tank. On the mediator Figure 4, the velocity is close to zero for low Reynolds numbers, but reaches a maximum with increasing relative inertia. Moreover, this maximum is lower than the end of the blade, which means that the flow rate in this zone is delayed beyond this maximum speed decreases as one approaches the tank, although more inclined than that from the ascending part of the curve. 
The influence of the Reynolds number on the profile of the radial velocity $\mathrm{Vr}^{*}$ on the blade Figure 5, we see thatthe variation of the radial velocity is perceptible Clearly between the axis of the agitator and the blade, this variation is rapidly decreasing at a low Reynolds number, we noted the existence of negative velocities which lead to the formation of the zone Recirculation at the vicinity of the blade and near the tank where the flow is delayed in this area. In addition, on the mediator Figure 6, the radial velocity is zero.

Figures 78910 show the variation of the tangential velocity and its extension and on the mediator for different concentrations for a flow regime $\mathrm{Re}=415$ and a nanofluid $(\mathrm{CuO})$, we note that there are no important variations because these quantities are local, similarly for the fluid nano $\left(\mathrm{Al}_{2} \mathrm{O}_{3}\right)$ figure. 11, 12 .

We note that the power number varies linearly with the inertia (Re) on a logarithmic scale, produced by the against Np*Re, the laminar flow constant is Re $<276$ equal to 800 for our mobile, all above this value, there is $\mathrm{Np} * \mathrm{Re}$, which means that energy consumption Reynold's number (figure 13, 14).

Figures 15 and 16 illustrate the variation of the power number $\mathrm{Np}$ as a function of the inertia and the product $\mathrm{Np} * \mathrm{Re}$ as a function of the concentration for a nanofluid $\left(\mathrm{Al}_{2} \mathrm{O}_{3}\right)$, there is a slight variation for low Reynolds numbers. As soon as the inertia is increased this variation becomes important, this can be explained by the large viscous forces in the case of nanofluids and is due to the improvement of the thermal conductivity of the nanofluid, when the volume fraction of the nanoparticles increases.

There is no variation of the tangential velocity on the blade and its extension and on the mediator between the two nanoparticles $\left(\mathrm{Al}_{2} \mathrm{O}_{3}\right.$ and Cuo) figure 17, 18. But the variation is remarkable in terms of number of power.

Figures 19, 20 represents the variation of the Reynolds number as a function of the volume fraction of the nanoparticles for different nanofluids and the product $\mathrm{Np*} \mathrm{Re}$. Note that the number of power $\mathrm{Np}$ for $\mathrm{CuO}$ is greater than $\mathrm{Al}_{2} \mathrm{O}_{3}$; this variation is remarkable for large Reynolds numbers.

\section{CONCLUSIONS}

The hydrodynamics of nanofluids in complex geometries such as stirring systems are modestly discussed. However, it plays an important role in the control and the effectiveness of the treatment because it conditions the transfer of heat and mass.

The problem is analyzed numerically. The latter is not treated by a code, but by using an existing industrial code which is the current code. The numerical simulations carried out in 2D geometries allowed to show significance by the rheological behavior of the fluid.

We used two types of nanofluids $\left(\mathrm{Al}_{2} \mathrm{O}_{3}+\right.$ water $),(\mathrm{CuO}+$ water $)$, each with different thermo physical properties. We have assumed that nanofluids can be assimilated to homogeneous fluids.

From our study, we have led to results that differ significantly from the results found by the many authors mentioned above.

It is true that the addition of $\left(\mathrm{Al}_{2} \mathrm{O}_{3}, \mathrm{CuO}\right)$ nanoparticles, in pure water increases its thermal conductivity and thus improves the conduction heat transfer in the nanofluids and also increases the energy consumption which is dissipated from the agitator to the fluid. 
The number of power is higher in the nanofluids compared to the base fluid and it has also been found that this number in the nanofluids increases with the increase in the concentration of the nanoparticles.

\section{ACKNOWLEDGEMENTS}

Many thanks are due to ENERGARID laboratory, especially the group of "rheology and agitation".

\section{NOMENCLATURE}

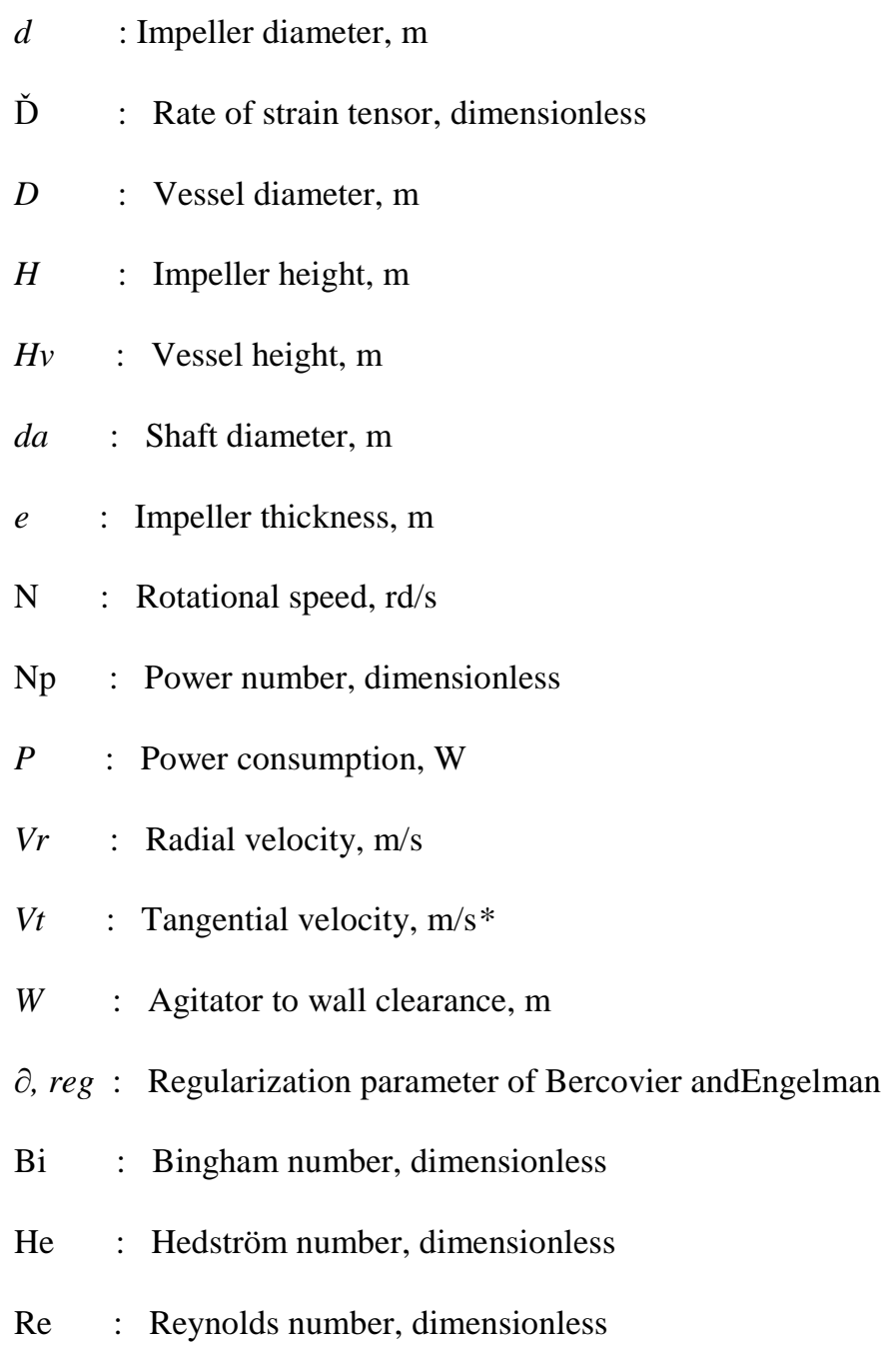

\section{Greek Symbols}

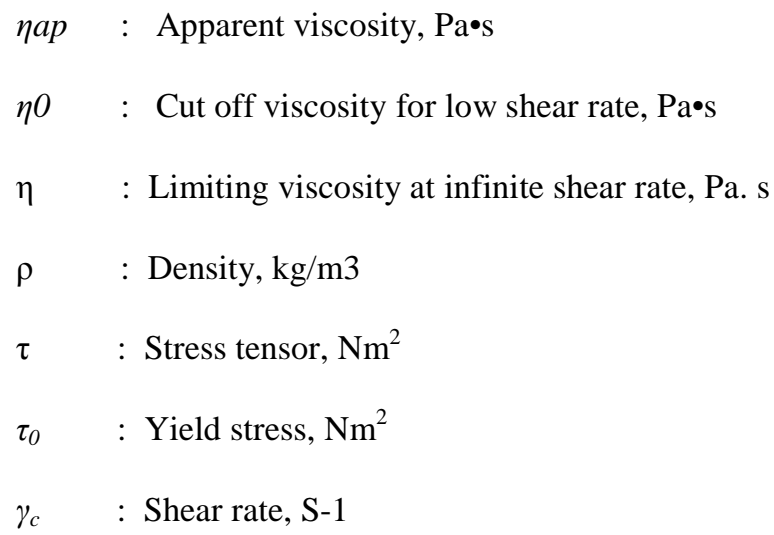


$\tau \quad:$ Cut off shear rate, Bingham model

\section{REFERENCES}

1. B. Gladés. Contribution à l'étude de la convection naturelledans les nanofluides en configuration de Rayleigh-Bénard. Thèse de doctorat de l'université de Toulouse, 14 octobre 2010.

2. S. U. S. Choi. Enhancing thermal conductivity of fluidswithnanoparticles, Developments and applications of NonNewtonianFlows. D. A. Siginer and H. P. Wang (Eds.), FED-vol. 231/MD-vol. 66, ASME, New York, 99-105, 1995.

3. S. U. S. Choi, Z. G. Zhang, W. Yu, F. E. Lockwood, and E. A Grulke. Anomalous thermal conductivity enhancement in nanotube suspension. Applied Physics Letters, 79(14): 2252-2254, 2001.

4. P. Keblinski, J. A. Eastman, and D. G. Cahill. Nanofluids for thermal transport. Materials today, 8, 36, 2005.

5. H. Masuda, A. Ebata, K. Teramae, and N. Hishinuma. Alteration of Thermal conductivity and viscosity of liquid by dispersing Ultra-fine Particles (dispersion of $\mathrm{Al}_{2} \mathrm{O}_{3}, \mathrm{SiO}_{2}$, and TiO $\mathrm{T}_{2}$ Ultra-fine particles). Netsu Bussei (Japan), 7(4): 227-233, 1993.

6. S. M. S. Murshed, K. C. Leong, and C. Yang. Thermal conductivity of nanoparticle suspensions. International Journal of thermal science, Singapore 2007.

7. H. Chen, Y. Ding, Y. He and C. Tan. Rheological behaviour of nanofluids. New Journal of Physics, 9, 367, 2007.

8. KerimYapici, BulentKarasozen, Michael Schafer, Yusuf Uludag. Numerical investigation of the effect of the Rushton type turbine design factors on agitated tank flow characteristics. Chemical Engineering and Processing, 2007.

9. F. Ein-Mozaffari, C. P. J. Bennington, G. A. Dumont, Suspension yield stress and the dynamic response of agitated pulp chests, Chem. Eng. Sci. 60, 2005.

10. T. P. Elson, The growth of caverns formed around rotating impellers during the mixing of a yield stress fluid, Chem. Eng. 96 303-319, 1990.

11. D. Anne-Archard, M. Marouche, H. C. Boisson. Hydrodynamics and Metzner-Otto correlation in stirred vessels for yield stress fluids. Chemical Engineering Journal, 125, 15-24, 2006.

12. J. N. Haque, T. Mahmud, K. Roberts, Modeling turbulent flows with freesurface in unbaffled agitated vessels, Ind. Eng. Chem. Res. 45, 2881-2891, 2006.

13. V. V. Ranade, S. M. S. Dommeti, Computational snapshot of flow generated by axial impellers in baffled stirred vessels, Trans. Inst. Chem. Eng. 74, 476-484, 1996.

14. J. J. Derksen, Numerical simulation of solid suspension in a stirred tank, Aiche J. 49, 2700-2714, 2003.

15. M. Marouche, Hydrodynamique d'un système d'agitation en fluide viscoplastique et en régime laminaire inertiel, Thèse de doctorat, Institut Nationale Polytechnique de Toulouse, 2002.

16. Nasrawi, H. K. R. Natural convection heat transfer inside an inclined square enclosure filled with al2o3 nanofluid in presence of pair of discrete heat flux sources in bottom wall.

17. L. Rahmanil et al. Heat transfer to Bingham fluid during laminar flow in agitated tank. International Review of Mechanical Engineering (I. RE. M. E.), Vol.09, 2013.

18. EJ. O'Donovan EJ, Tanner RI, Numerical analysis of the Bingham squeeze film problem, journal of Non-New. Flu. Mec. 15,75-83, 1984.

19. PATANKAR S. V. Numerical heat transfer and fluid flow. Mc-Graw Hill, 1980. 
20. G. C. Vradis, M. V. Otugen, The axisymmetric sudden expansion flow of a non-Newtonian viscoplastic fluid, J. Fluid Eng. 119,193-200, 1997.

21. M. Marouche, D. Anne-Archard, H. C. Boisson, A numerical model of yield stress fluid dynamics in a mixing vessel, Appl. Rheol. 12, 182-191, 2002.

22. M. Marouche, Hydrodynamique d'un système d'agitation en fluide viscoplastique et en régime laminaire inertiel, Thèse de Doctorat de l'INP Toulouse, France, 2002.

23. A. B. Metzner, R. E. Otto, Agitation of non-Newtonian fluids, Aiche J. 3, 3-10 (1957).

24. M. Kadja, A. Zaatri, Z. Nemouchi, R. Bessaih, S. Benissaadand K. Talbi. Simulation numérique du transfert de chaleur de nanofluide dans un canal. Third International Conference on Energy, Materials, Applied Energetic and Pollution. ICEMAEP, October30-31, 2016, Constantine, Algeria.

25. Gladés Bachir, Contribution à l'étude de la convection naturelle dans les nanofluides en configuration de Rayleigh-Bénard, thèse doctorat de l'université de Toulouse, 2010.

26. A. Mahboub. Etude Numériqued'un Ecoulement Turbulentdansune Cuve Agitéeparun Cylindre Magnétique. thèse de Magister université des sciences et de la technologie Oran, 2014.

27. W. Chamsa-ard, S. Brundavanam, C. H. Fung, D. Fawcett and G. Poinern. Nanofluid Types, TheirSynthesis, Properties and Incorporation in Direct Solar Thermal Collectors. Nanomaterials, 7, 131; doi:10.3390/nano7060131, 2017.

28. C. C. d. Santosa, W. R. Vialia, E. d. S. Nunesa, D. R. d. Assisa, B. E. Amantéaa, M. J. Júniora. Aqueous Nanofluids Based on Copper MPA: Synthesis and Characterization. Materials Research, 20(Suppl. 1), 104-110, 2017.

29. I. Ayranci, M. B. Machado, A. M. Madej, J. J. Derksen, D. S. Nobes, S. M. Kresta. Effect of geometry on the mechanisms for off- bottom solids suspension in a stirred tank. Chemical Engineering Science, 79, 163-176, 2012.

30. E. Alizadeh, F. Bertrand, J. Chaouki. Comparison of DEM results and Lagrangian experimental data for the flow and mixing of granules in a rotating drum. AIChE Journal, 60(1), 6075, 2014.

31. B. Mebarki, B. Draoui, L. RahmaniI, M. Bouanini et E. Benachour. Etude numérique de l'agitation d'un fluide viscoplastique au sein d'une cuve agitée par un mobile de type bipale.10th International Meeting on Energetical Physics. Journal of Scientific Research, vol. 1, 2010. 